\title{
Predictors of mortality in neonatal sepsis in a resource-limited setting
}

\section{Adonis Muganza Nyenga ${ }^{1}$, Olivier Mukuku², André Kabamba Mutombo ${ }^{3}$, Charles Wembonyama Mpoy ${ }^{4}$, Oscar Numbi Luboya $^{1,2}$ and Stanis Okitotsho Wembonyama ${ }^{1 *}$}

\author{
1'Department of Pediatrics, Faculty of Medicine, University of Lubumbashi, Lubumbashi, Democratic \\ Republic of Congo \\ ${ }^{2}$ Institut Supérieur des Techniques Médicales, Lubumbashi, Democratic Republic of Congo \\ ${ }^{3}$ Department of Pediatrics, Faculty of Medicine, University of Mbuyi-Mayi, Mbuji-Mayi, Democratic \\ Republic of Congo \\ ${ }^{4}$ Department of Obstetrics and Gynecology, Faculty of Medicine, University of Lubumbashi, Lubumbashi, \\ Democratic Republic of Congo
}

\section{Abstract}

Introduction: Sepsis remains a major cause of death in neonatal period. Although significant advances in diagnosis, therapeutic and prevention strategies have been noted, sepsis remains a common concern in clinical practice especially in low-resource countries. The aim of this study was to determine the predictors of mortality in neonatal sepsis in Lubumbashi city (Democratic Republic of Congo).

Methods: The records of newborns with sepsis managed in Neonatal Intensive Care Units in two University Hospitals between November 2019 and October 2020 were studied. Binary and multiple logistic regressions have been used to observe the association between independent variables and dependent variable.

Results: A total of 162 cases of neonatal sepsis were reviewed. The mortality rate of neonatal sepsis was $21 \%$ of babies admitted. Very low birth weight (< 1500 grams) and primiparity were significantly associated with mortality in neonatal sepsis (AOR $=12.66 ; 95 \% \mathrm{Cl} 2.40$ to 66.86 ; $p=0.003$ and $\mathrm{AOR}=3.35 ; 95 \% \mathrm{Cl} 1.31$ to $8.59 ; p=0.012$, respectively).

Conclusion: The mortality rate of neonatal sepsis was $21 \%$. Very low birth weight and primiparity were significantly associated with mortality in neonatal sepsis.

\section{More Information}

*Address for Correspondence:

Dr. Stanis Okitotsho Wembonyama, Professor, Department of Pediatrics, Faculty of Medicine, University of Lubumbashi, Lubumbashi, Democratic Republic of Congo,

Email:wembostanis@outlook.fr

Submitted: May 12, 2021

Approved: June 15, 2021

Published: June 16, 2021

How to cite this article: Nyenga AM, Mukuku O, Mutombo AK, Mpoy CW, Luboya ON, et al. Predictors of mortality in neonatal sepsis in a resource-limited setting. J Adv Pediatr Child Health. 2021; 4: 057-061.

DOI: 10.29328/journal.japch.1001034

Copyright: @ 2021 Nyenga AM, et al. This is an open access article distributed under the Creative Commons Attribution License, which permits unrestricted use, distribution, and reproduction in any medium, provided the original work is properly cited.

Keywords: Neonatal sepsis; Risk factors; Mortality; Lubumbashi

A) Check for updates

Open Access

\section{Introduction}

Neonatal sepsis (NS) is a systemic infection that occurs in newborns under 28 days of life. It is a condition of bacterial, viral or fungal origin which is accompanied by a range of clinical manifestations $[1,2]$. The newborns exposed to these pathogens during the perinatal period are sensitive to invasive infections because of their relatively weakened immune system [3]. The incidence of NS varies from 1 to 170 per 1,000 live births [4.5]. In Lubumbashi (in the Democratic Republic of the Congo [DRC]), it was $31.39 \%$ [6].

NS remains a major cause of death in this population, although significant advances in diagnosis, therapeutic and prevention strategies [2]. In 2019, the World Health Organization (WHO) estimated that $2.4(2.3-2.7)$ million newborns died within 28 days of birth [7]. The main causes of these neonatal deaths were infections (35\%), premature births (28\%), intrapartum complications (24\%) and asphyxia (23\%). In developing countries, each year, sepsis is the most common cause of neonatal mortality and is probably responsible for 30 to $50 \%$ of the total neonatal deaths [8.9]. Nyenga, et al. [10], in a recent study conducted in Lubumbashi (in the DRC), reported that sepsis was responsible for $21 \%$ neonatal deaths.

The purpose of our study was to identify the factors associated with NS mortality in Lubumbashi, DRC.

\section{Methodology}

We conducted an analytical cross-sectional study in 
Neonatal Intensive Care Units in two University Hospitals in Lubumbashi (University Clinics and Sendwe Hospital) in the Haut-Katanga Province in the November 2019 to October 2020. We included all the newborn admitted NS in neonatal intensive care units of these tertiary care hospitals. The recruitment of the subjects was exhaustive and consecutive to the oral consent of their mother. The sample size was 162 .

NS is a clinical syndrome with or without a bacteremia occurring during the first month of life. In this study, sepsis has been diagnosed on the basis of clinical symptoms by applying the criteria of the WHO [11,12]. This clinical diagnosis was supplemented by the iterative dosage of the $\mathrm{C}$-reactive protein at a significant threshold $\geq 20 \mathrm{mg} / \mathrm{L}$ from the 24 th hour after suspicion of the infection.

NS was classified in early onset sepsis (EONS) if it occurred at the beginning of 72 hours of life and late onset sepsis (LONS) if it occurred after 72 hours of life. The results have been defined as the condition of the patient at the exit and grouped by living and deceased. The variables studied were related to: maternal sociodemographic characteristics (age, parity, marital status, level of education, occupation) and neonatal characteristics (gestational age, birth weight, sex, delivery routes, admission mode, type of sepsis, concept of medical assistance and presence of antecedent of infectious risk).

Data were analyzed using the Stata software (version 15.0). Variables have been categorized and summarized in percentages. A bivariate analysis was performed followed by a multivariate analysis to reduce the effect of confounding factors. Adjusted odds ratios (AOR) with Confidence intervals of $95 \%$ ( $95 \% \mathrm{CI}$ ) were used to measure the degree of association between the variables. A $p$ - value of 0.05 was considered statistically significant.
Ethical authorization was obtained from the Medical Ethics Committee of the University of Lubumbashi (Approval No. UNILU/CEM/038/2019). The privacy of the respondent and the confidentiality of the information has been ensured throughout the study procedure.

\section{Results}

We found that most cases of NS occurred in male newborns (51.85\%), those born at term (68.52\%), those born with low weight $(52.46 \%)$, and those born spontaneously by vaginal route $(71.6 \%)$.

Of the 162 newborns with NS, most cases (93.21\%) were EONS. Most patients (82.72\%) had at least one infectious risk factor; the main maternal risk factors identified were genitourinary tract infections (42.59\%), premature membrane rupture (32.10\%), meconium-stained amniotic fluid (25.31\%) and prolonged labor $(20.37 \%)$.

The mortality rate was $21 \%$. In a bivariate analysis, NS-related mortality was significantly correlated with: primiparity $(\mathrm{OR}=2.56[1.17-5.59] ; p=0.016)$, admission mode $(\mathrm{OR}=2.50$ [1.16-5.41]; $p=0.017$ ), gestational age $<37$ weeks $(\mathrm{OR}=3.80$ [1.73-8.34]; $p=0.0005)$, birth weight $<1500$ grams $(\mathrm{OR}=12.59$ [4.27-37.10]; $p<0.0001)$, and non-medical assistance at birth (OR $=2.49$ [1.08-5.74]; $p=0.029$ ) (Tables 1 and 2). Further analysis by multivariate logistic regression showed that primiparity (adjusted OR = 3.35 [1.31-8.59]; $p=0.012$ ) and birth weight $<1500$ grams (adjusted OR = 12.66 [2.40-66.86]; $p=0.003$ ) were significantly associated with NS-related mortality (Table 3).

\section{Discussion}

The neonatal mortality rate is a reliable criterion for assessing the overall progress of perinatal care in a

Table 1: Unadjusted association between neonatal sepsis related mortality and socio-demographic characteristics of mothers.

\begin{tabular}{|c|c|c|c|c|c|c|c|}
\hline \multirow{2}{*}{$\begin{array}{c}\text { Variable } \\
\text { Maternal age }\end{array}$} & \multicolumn{5}{|c|}{ Neonatal sepsis } & \multirow[b]{2}{*}{ Crude OR $[95 \% \mathrm{CI}]$} & \multirow[b]{2}{*}{$p$ - value } \\
\hline & $\begin{array}{c}\text { Total } \\
(\mathbf{N}=162)\end{array}$ & \multicolumn{2}{|c|}{$\begin{array}{l}\text { Non survivor } \\
\quad(n=34)\end{array}$} & \multicolumn{2}{|c|}{$\begin{array}{l}\text { Survivor } \\
(n=128)\end{array}$} & & \\
\hline$<20$ years & 28 & 9 & $32.14 \%$ & 19 & $67.86 \%$ & 1.67 [0.67-4.18] & 0.272 \\
\hline $20-34$ years & 104 & 23 & $22.12 \%$ & 81 & $77.88 \%$ & Reference & \\
\hline$\geq 35$ years & 30 & 2 & $6.67 \%$ & 28 & $93.33 \%$ & $0.25[0.03-1.14]$ & 0.065 \\
\hline \multicolumn{8}{|l|}{ Parity } \\
\hline Primiparous & 49 & 16 & $32.65 \%$ & 33 & $67.35 \%$ & 2.56 [1.17-5.59] & 0.016 \\
\hline Multiparous & 113 & 18 & $15.93 \%$ & 95 & $84.07 \%$ & Reference & \\
\hline \multicolumn{8}{|l|}{ Marital status } \\
\hline Single & 15 & 5 & $33.33 \%$ & 10 & $66.67 \%$ & 2.03 [0.64-6.41] & 0.218 \\
\hline Married & 147 & 29 & $19.73 \%$ & 118 & $80.27 \%$ & Reference & \\
\hline \multicolumn{8}{|l|}{ Education level } \\
\hline Primary & 20 & 5 & $25.00 \%$ & 15 & $75.00 \%$ & 1.51 [0.45-5.05] & 0.497 \\
\hline Secondary & 81 & 18 & $22.22 \%$ & 63 & $77.78 \%$ & $1.30[0.56-3.00]$ & 0.539 \\
\hline Higher/University & 61 & 11 & $18.03 \%$ & 50 & $81.97 \%$ & Reference & \\
\hline \multicolumn{8}{|l|}{ Profession } \\
\hline Student & 3 & 2 & $66.67 \%$ & 1 & $33.33 \%$ & 14.67 [0.61-526.05] & 0.056 \\
\hline Functionary & 21 & 4 & $19.05 \%$ & 17 & $80.95 \%$ & $2.01[0.30-15.48]$ & 0.434 \\
\hline Liberal & 29 & 3 & $10.34 \%$ & 26 & $89.66 \%$ & Reference & \\
\hline Housewife & 109 & 25 & $22.94 \%$ & 84 & $77.06 \%$ & $2.56[0.69-14.33]$ & 0.194 \\
\hline
\end{tabular}

N: Number; OR: Odds Ratio; $95 \% \mathrm{Cl}$ : Confidence Interval at $95 \%$. 
Table 2: Unadjusted association between neonatal sepsis related mortality and neonatal characteristics.

\begin{tabular}{|c|c|c|c|c|c|c|c|}
\hline \multirow{3}{*}{$\begin{array}{c}\text { Variable } \\
\text { Type of sepsis }\end{array}$} & \multicolumn{5}{|c|}{ Neonatal sepsis } & \multirow[b]{2}{*}{ Crude OR $[95 \% \mathrm{Cl}]$} & \multirow[b]{2}{*}{$p$-value } \\
\hline & \multirow[t]{2}{*}{$\begin{array}{c}\text { Total } \\
(\mathrm{N}=162)\end{array}$} & \multicolumn{2}{|c|}{$\begin{array}{l}\text { Non survivor } \\
\quad(n=34)\end{array}$} & \multicolumn{2}{|c|}{$\begin{array}{l}\text { Survivor } \\
(n=128)\end{array}$} & & \\
\hline & & & & & & & \\
\hline EONS & 151 & 32 & $21.19 \%$ & 119 & $78.81 \%$ & $1.21[0.23-12.04]$ & 1.000 \\
\hline LONS & 11 & 2 & $18.18 \%$ & 9 & $81.82 \%$ & Reference & \\
\hline \multicolumn{8}{|l|}{ Transfer from another hospital } \\
\hline Yes & 62 & 19 & $30.65 \%$ & 43 & $69.35 \%$ & $2.50[1.16-5.41]$ & 0.017 \\
\hline No & 100 & 15 & $15.00 \%$ & 85 & $85.00 \%$ & Reference & \\
\hline \multicolumn{8}{|l|}{ Gestational age } \\
\hline$<37$ weeks & 51 & 19 & $37.25 \%$ & 32 & $62.75 \%$ & $3.80[1.73-8.34]$ & 0.0005 \\
\hline$\geq 37$ weeks & 111 & 15 & $13.51 \%$ & 96 & $86.49 \%$ & Reference & \\
\hline \multicolumn{8}{|l|}{ Sex } \\
\hline Female & 78 & 19 & $24.36 \%$ & 59 & $75.64 \%$ & Reference & \\
\hline Male & 84 & 15 & $17.86 \%$ & 69 & $82.14 \%$ & $1.48[0.69-3.17]$ & 0.310 \\
\hline \multicolumn{8}{|l|}{ Birth weight } \\
\hline$<1500$ grams & 24 & 15 & $62.50 \%$ & 9 & $37.50 \%$ & $12.59[4.27-37.10]$ & $<0.00001$ \\
\hline 1500-2499 grams & 61 & 10 & $16.39 \%$ & 51 & $83.61 \%$ & $1.48[0.56-3.91]$ & 0.426 \\
\hline$\geq 2500$ grams & 77 & 9 & $11.69 \%$ & 68 & $88.31 \%$ & Reference & \\
\hline \multicolumn{8}{|l|}{ Delivery mode } \\
\hline Obstructed vaginal delivery & 4 & 1 & $25.00 \%$ & 3 & $75.00 \%$ & $0.96[0.10-9.54]$ & 1.000 \\
\hline Caesarean section & 42 & 3 & $7.14 \%$ & 39 & $92.86 \%$ & $0.22[0.06-0.77]$ & 0.013 \\
\hline Eutocical delivery & 116 & 30 & $25.86 \%$ & 86 & $74.14 \%$ & Reference & \\
\hline \multicolumn{8}{|l|}{ Medical assistance at birth } \\
\hline No & 35 & 12 & $34.29 \%$ & 23 & $65.71 \%$ & $2.49[1.08-5.74]$ & 0.029 \\
\hline Yes & 127 & 22 & $17.32 \%$ & 105 & $82.68 \%$ & Reference & \\
\hline \multicolumn{8}{|l|}{ Infectious risk } \\
\hline Yes & 134 & 29 & $21.64 \%$ & 105 & $78.36 \%$ & $1.27[0.44-3.63]$ & 0.655 \\
\hline No & 28 & 5 & $17.86 \%$ & 23 & $82.14 \%$ & Reference & \\
\hline
\end{tabular}

Table 3: Multiple logistic regression of risk factors for neonatal sepsis related mortality in newborns in Lubumbashi.

\begin{tabular}{|c|c|c|c|c|c|c|}
\hline Variable & Adjusted OR & St. Error & $\mathrm{t}$-value & $p$-value & \multicolumn{2}{|c|}{ [95\% Confidence Interval] } \\
\hline \multicolumn{7}{|l|}{ Medical assistance at birth } \\
\hline Yes & 2.09 & 1.13 & 1.36 & 0.174 & 0.72 & 6.04 \\
\hline No & Ref. & & & & & \\
\hline \multicolumn{7}{|l|}{ Delivery mode } \\
\hline Obstructed vaginal delivery & 2.36 & 3.02 & 0.67 & 0.503 & 0.19 & 29.05 \\
\hline Cesarean section & 0.57 & 0.41 & -0.78 & 0.434 & 0.14 & 2.30 \\
\hline Eutocical delivery & Ref. & & & & & \\
\hline \multicolumn{7}{|l|}{ Gestationnel age } \\
\hline$<37$ weeks & 0.99 & 0.66 & -0.01 & 0.992 & 0.27 & 3.62 \\
\hline$\geq 37$ weeks & Ref. & & & & & \\
\hline \multicolumn{7}{|l|}{ Birth weight } \\
\hline$<1500$ grams & 12.66 & 10.75 & 2.99 & 0.003 & 2.40 & 66.86 \\
\hline 1500-2499 grams & 1.82 & 1.14 & 0.96 & 0.339 & 0.53 & 6.19 \\
\hline$\geq 2500$ grams & Ref. & & & & & \\
\hline \multicolumn{7}{|l|}{ Parity } \\
\hline Primiparous & 3.35 & 1.61 & 2.52 & 0.012 & 1.31 & 8.59 \\
\hline Multiparous & Ref. & & & & & \\
\hline \multicolumn{7}{|l|}{ Transfer from another hospital } \\
\hline Yes & 2.31 & 1.19 & 1.62 & 0.106 & 0.84 & 6.35 \\
\hline No & Ref. & & & & & \\
\hline
\end{tabular}

community. Knowledge of local or regional health problems is a prerequisite for an effective health care delivery system [13]. The mortality rate of NS varies between hospitals and between countries. This study reports a mortality rate of $21 \%$. Comparable rates have been found in other studies conducted in India (16\%) [14], Nigeria (19.3\%) [15], South Africa (20.8\%) [16] and Indonesia (28.3\%) [17]. While high rates were reported in Nigeria (32.2\%) [18], India (38.24\%) [19],
Mexico (43.9\%) [20], and Iraq (44.2\%) [13]. These differences in mortality rates between studies are attributable to many factors such as socio-economic factors, geographical factors, equipment levels and the effectiveness of each hospital's prophylactic and therapeutic approach [13]. NS may have subtle, diverse and non-specific symptoms and signs, often leading to delayed diagnosis and treatment leading to high morbidity and mortality [21]. 
We found that primiparity was a risk factor for neonatal death in the case of sepsis. Munan, et al. [22] reported that perinatal death was higher in primipares than in multipares and noted that the need for neonatal intensive care was significantly recorded in primiparous newborns. According to these authors, this would be due to high rates of intrapartal complications (prolonged or obstructed labour, dystocies, caesarean sections, fetal distress, poor Apgar scores) in primipares [22]. The same finding was reported by Kaur and Kaur, [23]. Although these authors did not take an interest in NS, it is logical that this finding is also applicable in the case of NS. This combination of primiparity-related morbid events could compromise the life-threatening prognosis of the newborn with sepsis. Primiparous newborn is therefore considered to be at risk and gestation as the postnatal period should be given special care [24]. Trotman, et al. [25] found an association between early childhood and death in neonates with sepsis. Similarly, young age may be considered a characteristic of primiparous mothers in our contexts where the prevalence of teenage motherhood is high [26]. In our series, we found a high death rate among mothers under 20 years of age (32.1\%) although this association with maternal age was not statistically significant. Lack of experience with lower-risk behavior during pregnancy would also be an important factor.

This study showed that low birth weight $(<1500$ grams $)$ was a risk factor for death in neonates with sepsis. A similar finding has been reported in many previous studies in different countries $[13,14,19,20]$. Infectious disease morbidity and mortality are known to be high in low-birth-weight infants [27]. This is explained either by an inherent immune deficiency or because these newborns require prolonged hospitalization that increases the risk of nosocomial infection. Infection is therefore added to all the complications that already darken the life-threatening prognosis of low-birth-weight infants. Transplacental maternal antibodies are mainly involved in humoral and cellular immunity, so premature neonates are less likely to receive as many immunoglobulins as neonates born at term [25]. Indeed, although prematurity in general is not a statistically related factor to NS-related mortality in our series, we nonetheless noted a high mortality rate in premature neonates (37.3\%).

The results of this study should be interpreted with certain limitations. First, because of the cross-sectional nature of the study. Secondary to the fact that the study is conducted with newborns admitted to urban reference hospitals, the results may not be generalizable to the general population.

\section{Conclusion}

This study identified primiparity and very low birth weight as independent risk factors for mortality in NS. Strategies to reduce morbidity and mortality in newborns with sepsis should include measures that will reduce the incidence of low birth weight or even premature birth. Primiparity will need to be given particular attention in programs to monitor motherto-child infections and to manage the risk of sepsis-related complications.

\section{References}

1. Shane AL, Sánchez PJ, Stoll BJ. Neonatal sepsis. Lancet. 2017; 390: 1770-1780.

PubMed: https://pubmed.ncbi.nlm.nih.gov/28434651/

2. Pek JH, Gan MY, Yap BJ, Seethor STT, Greenberg RG, et al. Contemporary trends in global mortality of sepsis among young infants less than 90 days old: protocol for a systematic review and metaanalysis. BMJ Open. 2020; 10: e038815.

PubMed: https://pubmed.ncbi.nlm.nih.gov/32737098/

3. Shane AL, Stoll BJ. Neonatal sepsis: progress towards improved outcomes. J Infect. 2014; 68: S24-32.

PubMed: https://pubmed.ncbi.nlm.nih.gov/24140138/

4. Cortese F, Scicchitano P, Gesualdo M, Filaninno A, De Giorgi E, et al Early and Late Infections in Newborns: Where Do We Stand? A Review. Pediatr Neonatol. 2016; 57: 265-273.

PubMed: https://pubmed.ncbi.nlm.nih.gov/26750406/

5. Bohanon FJ, Nunez Lopez O, Adhikari D, Mehta HB, Rojas-Khalil Y, et al. Race, Income and Insurance Status Affect Neonatal Sepsis Mortality and Healthcare Resource Utilization. Pediatr Infect Dis J. 2018; 37: e178-e184.

PubMed: https://www.ncbi.nlm.nih.gov/pmc/articles/PMC5953763/

6. Nyenga AM, Mukuku O, Kabamba Mutombo A, Luboya ON, Wembonyama SO. Epidémiologie de la septicémie néonatale à Lubumbashi, République démocratique du Congo. J Med Public Health Policy Res. 2021; 1: 6-13. Disponible sur: http://pugoma.com/index.php/JMPHPR/article/view/40

7. UN Inter-agency Group for Child Mortality Estimation. Levels and Trends in Child Mortality: 2020 Report. United Nations Children's Fund (UNICEF), World Health Organization (WHO), World Bank Group, and United Nations Population Division; 2020.

https://www.un.org/development/desa/pd/news/levels-and-trendschild-mortality-2020-report

8. Agnche Z, Yeshita HY, Gonete KA. Neonatal Sepsis and Its Associated Factors Among Neonates Admitted to Neonatal Intensive Care Units in Primary Hospitals in Central Gondar Zone, Northwest Ethiopia. 2019. Infect Drug Resist. 2020; 13: 3957-3967.

PubMed: https://pubmed.ncbi.nlm.nih.gov/33177846/

9. Getabelew A, Aman M, Fantaye E, Yeheyis T. Prevalence of neonatal sepsis and associated factors among neonates in neonatal intensive care unit at selected governmental hospitals in Shashemene Town, Oromia Regional State, Ethiopia, 2017. Int J Pediatr. 2018; 2018. PubMed: https://pubmed.ncbi.nlm.nih.gov/30174698/

10. Nyenga AM, Malonda BN, Abdala AK, Assumani AN, Mukuku O, et al. Trends in Neonatal Mortality in Lubumbashi (Democratic Republic of Congo) from 2011 to 2018. Clin Pediatri. 2019; 2: 1017.

11. Kayom VO, Mugalu J, Kakuru A, Kiguli S, Karamagi C. Burden, and factors associated with clinical neonatal sepsis in urban Uganda: a community cohort study. BMC Pediatr. 2018; 18: 355

12. World Health Organisation and UNICEF. Handbook: IMCI integrated management of childhood illness. Geneva: WHO. 2005. PubMed: https://www.ncbi.nlm.nih.gov/pmc/articles/PMC2083332/

13. Sabeeh Jumah D. Predictors of mortality outcome in neonatal sepsis. Med J Basrah Univers. 2007; 25: 11-18.

14. Sharma R, Soni TN, Rathore R, Rajput JS. A prospective study of risk factors of mortality in neonatal sepsis patients. Int J Med Res. 2018; 3: $72-74$.

15. Ezechukwa CC, Ugochukwu A, Egbuonu I, et al. Risk Factors for neonatal mortality in a regional tertiary hospital in Nigeria. Nigerian $\mathrm{J}$ Clin Practice. 2004; 7: 50-52. 
16. Motara F, Ballot DE, Perovic O. Epidemiology of Neonatal Sepsis at Johannesburg Hospital. Southern African J Epidemiol Infect. 2005; 20 : 90-93.

17. Kardana IM. Incidence and factors associated with mortality of neonatal sepsis. Paediatrica Indonesiana. 2011; 51: 144-148.

18. Ogunlesi TA, Ogunfowora OB. Predictors of mortality in neonata septicemia in an underresourced setting. J Natl Med Assoc. 2010; 102 915-922.

PubMed: https://pubmed.ncbi.nlm.nih.gov/21053706/

19. Meshram RM, Gajimwar VS, Bhongade SD. Predictors of mortality in outborns with neonatal sepsis: A prospective observational study Niger Postgrad Med J. 2019; 26: 216-222.

PubMed: https://pubmed.ncbi.nlm.nih.gov/31621661/

20. Rodriguez M, Canadiani C, Garcia J, Gutiérrez-Castrellón P, SánchezArriaga F. Morbidity and Mortality from neonatal sepsis in a tertiary care level hospital. Salud Publica de Mexico. 2003; 45: 90-95.

PubMed: https://pubmed.ncbi.nlm.nih.gov/12736986/

21. Ahmed Z, Ghafoor T, Waqar T, Ali S, Aziz S, et al. Diagnostics value of $\mathrm{C}$-reactive protein and hematological parameters in neonatal sepsis. J Coll Physician Surg Pak. 2005; 15: 152-156.

PubMed: https://pubmed.ncbi.nIm.nih.gov/15808093/

22. Munan R, Kakudji Y, Nsambi J, Mukuku O, Maleya A, et al
Accouchement chez la primipare à Lubumbashi : pronostic maternel et périnatal. Pan African Med J. 2017; 28: 77.

PubMed: https://www.ncbi.nlm.nih.gov/pmc/articles/PMC5724725/

23. Kaur J, Kaur K. Obstetric complications: primiparity vs. multiparity. Eur J Experimen Biol. 2012; 2: 1462-1468.

24. Kakudji PL, Mukuku O, Tambwe AM, et al. Etude du pronostic maternel et périnatal au cours de l'accouchement chez l'adolescente à Lubumbashi, République Démocratique du Congo. Pan African Med J. 2017; 26.

25. Trotman H, Bell Y, Thame M, Nicholson AM, Barton M. Predictors of poor outcome in neonates with bacterial sepsis admitted to the University Hospital of the West Indies. West Indian Med J. 2006; 55: 80-84. PubMed: https://pubmed.ncbi.nlm.nih.gov/16921699/

26. Belinda $\mathrm{M}$, Linda $\mathrm{R}$, Jay $\mathrm{K}$, et al. Lois sur l'âge minimum du mariage et prévalence du mariage précoce et de la maternité à l'adolescence: données d'Afrique subsaharienne. Perspectives sexuelles sur la santé sexuelle et génésique. 2016; 29-39.

27. Valero De Bernabe J, Soriano T, Albaladejo R, Juarranz M, Calle ME, et al. Risk factors for low birth weight: a review. Eur J Obstet Gynecol Reprod Biol. 2004; 116: 3-15.

PubMed: https://pubmed.ncbi.nlm.nih.gov/15294360/ 